\title{
FORENSIC PSYCHOLINGUISTICS: USING LANGUAGE ANALYSIS FOR IDENTIFYING AND ASSESSING OFFENDERS
}

\author{
Nareeman Jabbar Rasheed \\ Instructor, Department of English \\ College of Education for women, University of Baghdad, Baghdad, Iraq
}

DOI: $10.37648 /$ ijrssh.v10i01.040

Received:17 $7^{\text {th }}$ November 2019; Accepted:15 $5^{\text {th }}$ December, 2019; Published:06 ${ }^{\text {th }}$ January, 2020

\begin{abstract}
Forensic Linguistics (FL) is a relatively new subfield within applied linguistics that studies the different interactions between language and legal field, which is heavily linguistic by nature. In order to have a fair, legal and effective procedures, anyone involved in a legal process (lawyers, judges, police officers, members of a jury, etc.) benefits from possessing a certain awareness of linguistic principles. With this purpose, the expert testimony of a linguist could contribute to the understanding or recognition of possible interpretations or points of view that might have gone otherwise unnoticed. This article provides the general linguist with an overview of the broad field of FL and highlights the different ways the discipline can contribute to the criminal justice system. It presents a summary of some of the most well-known and discussed legal cases and outlines the interactions between applied linguistics ( main branches, discourse and pragmatics, and semantics).
\end{abstract}

Keywords:forensic linguistics, psycholinguistic forensic texts, discourse and pragmatics

\section{INTRODUCTION}

\subsection{The Problem}

Generally speaking, forensic linguistics or the language and the law is the application of linguistic knowledge, methods and insights to the forensic context of law, language, crime investigation, trial, and the judicial procedure. It is a branch of applied linguistics.

The phrase forensic linguistics first appeared in 1968 when Jan Svartvik, a professor of linguistics, used it in an analysis of statements by Timothy John Evans. It was in regard to re-analyzing the statements given to police at Notting Hill Police station in 1949 in the case of an alleged murder by Evans. Evans was suspected of murdering his wife and baby and was tried and hanged for the crime. Yet, when Svartvik studied the statements allegedly given by Evans, he found that there were different stylistic markers involved, and Evans did not actually give the statements to the police officers as had been stated at the trial.

\subsection{Aims of the Study}

The present study aims at:

1. Explaining the concepts of forensic psychological linguistics.

2. Identifying the linguistic areas of assessing language offenders.

\subsection{Scope of the Study}

The study is confined to the examination of the forensic linguistics such as the definitions of forensic linguistics, forensic stylistic, and the discourse and pragmatics of the forensic linguistics....etc. 


\subsection{Procedures of the Study}

The procedures used in this study can be summarized as follows:

1. Dividing the research into three sections. Section One is preliminaries that make the reader ready up to read the research and focus on its topic.

2. Section two is the core of the study which deals with many aspects of the subject which are the explanations of forensic linguistics.

3. Section three is the main concluding remarks that have been reached at throughout the work.

\section{FORENSIC LINGUISTICS}

\subsection{Introduction}

Forensic linguistics is a relatively new field within the scope of the field of Applied Linguistics. It can be defined as the application of linguistic knowledge to a particular social setting, namely the legal forum (from which the word forensic is derived). In its broadest sense, we may say that forensic linguistics is the interface between language, crime and law, where law includes law enforcement, judicial matters, legislation, disputes or proceedings in law, and even disputes which only potentially involve some infraction of the law or some necessity to seek a legal remedy (Olsson, 2008a, p.3).

\subsection{Definitions of Forensics Linguistics}

Forensics Linguistics is the scientific language as applied to forensic purposes and contexts. It is a very new area of linguistics vis-a-vis its 2400 -year history and is a recent and rapidly growing areas of modern applied linguistics. Linguists who did much of the groundbreaking work in forensic linguistics are often heard to say that what they do is linguistics that happens to be in a forensic context, and that a forensic linguist must first be a good linguist. Such observations are not meant to minimize the task of learning how to function within the judicial system, but they do signal the primary importance of the connection forensic linguistics has a discipline to the scientific theories and methods developed over time within general and applied linguistics. The purpose of this chapter is to trace the foundations of forensic linguistics and to outline specific areas of current research and practice within the field (McMenamin, 2002, p.33).

Crystal (2008, p.194) defines forensic is the use of linguistic techniques to investigate crime in which language data forms part of the evidence, such as in the use of grammatical or lexical criteria to authenticate police statements. The field of forensic phonetics is often distinguished as a separate domain, dealing with such matters as speaker identification, voice line-ups, speaker profiling, tape enhancement, tape authentication, and the decoding of disputed utterances. From the above, forensic linguistics, legal linguistics, or language and the law, is the application of linguistic knowledge, methods and insights to the forensic context of law, language, crime investigation, trial, and judicial procedure. It is a branch of applied linguistics for a better understanding of the language of the written law, and language use in the different forensic and judicial processes.

2.3 The Types of psycholinguistic Forensic Texts These types of forensic texts can be summarized as follows:

\subsubsection{Emergency Call}

In an emergency call, the recipient or emergency operator's ability to extract primarily linguistic information in threatening situations and to come up with the required response in a timely manner is crucial to the successful completion of the call. Intonational emphasis, voice pitch and the extent to which there is cooperation between the caller and the recipient at any one time are also very important in analyzing an emergency call. Full cooperation includes frank and timely responses.

Urgency plays a role in emergency calls, so hesitation, signs of evasiveness, and incomplete or overtly short answers indicates that the caller might be making a false or hoax call. A genuine call has distinctive interlocking and slight overlap of turns. The recipient trusts the caller to provide accurate information and the caller trusts the recipient to ask only pertinent questions. If the caller uses a rising pitch at the end of every turn, it might represent a lack of commitment; the recipients use of a rising pitch indicates doubt or desire for clarification. The call ideally moves from nil knowledge on the part of the recipient to a maximum amount of knowledge in a minimum possible period of time. This makes the emergency call unlike any other kind of service encounter (Olsson, 2008b, p.109).

\subsubsection{Ransom Demands or Other Threat Communication}

Threat is a counterpart of a promise and is an important factor in a ransom demand. Ransom demand are also examined to identify between genuine and false threats. An example of a ransom note analysis can be seen in the case of Lindbergh kidnapping, where the first ransom note (sometimes referred to as the Nursery Note) stated: "We warn you for making any ding public or for notify the 
Police the child is in gut care" (sic). From the sentence, the kidnapper makes the claim, the note would have to be written before the perpetrator enters the premises. Therefore, the claim is false (at the time of writing) since the kidnapper had not even encountered the child when he wrote the note. Kidnappers may write statements that later end up being true, such as "your child is being held in a private location" being written ahead of time (Falzini, 2008, p.9).

\subsubsection{Suicide Letters}

A suicide note is typically brief, concise and highly propositional with a degree of evasiveness. A credible suicide letter must be making a definite unequivocal proposition in a situational context. The proposition of genuine suicide is thematic, directed to the addressee (or addressees) and relevant to the relationship between them. Suicide notes generally have sentences alluding to the act of killing oneself, or the method of suicide that was undertaken. The content of a suicide note could be intended to make the addressee suffer or feel guilt. Genuine suicide letters are short, typically less than 300 words in length. Extraneous of irrelevant material is often excluded from the text (Falzini, p.9).

\subsection{Discourse and Pragmatics as a Forensic Psychological Linguistic Area}

Analysis of discourse is the study of units of language larger than the sentences, such as narratives and conversations. Discourse is spoken and written language can be take many forms, espionage in conversations tied to specific social contexts. The social context of discourse is determined by variable factors such as the speaker and hearer, their social roles, their personal and professional relationship, topic, purpose, time and place, etc. Analysis of a speaker's intended meaning is actual language use in the study of pragmatics. Pragmatics is important for forensic purposes because speakers and writers do not always directly match their words with the meaning that they intend to convey. Since listeners and readers may also be unsuccessful in matching expression to intended meaning, the speaker's or writer's intended meaning is more open to interpretation by the listener or reader, sometimes resulting in mistaken understanding, miscommunication, and eventually, conflict. The linguist and practitioner (expert witness) who systemically developed forensic discourse analysis for a broad range of cases is Roger Shuy. These cases go back at least to the mid 1980s and are documented in his research, especially in Language Crime: The use and Abuse Language
Evidence in the Countroom (Shuy, 1993), and in The Language of Confessions, Interrogation and Deception (McMenamin,

\subsection{Language of the Law as an Area of Forensic Psycholinguistics}

Perhaps the most important development to the language of the law was begun by David Melinkoff in his 1963 book, The Language of the Law. Melinkoff pressed for clarity and brevity in the law, which extended to a later movement to simplify the language of laws, insurance policies, and consumer literature. He was very direct in his prescriptions for good writing, once saying that the most effective way of shortening law language is for judges and lawyers to stop writing. Today, systematic analysis of legal language is represented by work such as that of Goodrich (1987), Conley and O'Barr (1998), and others; the plain language campaign has been taken up by Tiersma (1999), who has also expanded into other linguistically relevant aspects of legal language (McMenamin, p.46).

\subsection{Forensic Stylistic}

This discipline subjects written or spoken material (or both), to scientific analysis for determination of content, meaning, speaker identification, or determination of authorship, in identifying plagiarism (How does forensic linguistics/stylistics work in criminal issues?, 2014).

One of the earliest cases where forensic stylistics was used to detect plagiarism was the case of Helen Keller's short story "The Forst King", in which the blind American author was accused of plagiarism in 1992. An investigation revealed that "The Forst King" has been plagiarized from Margaret Canby's Forst Fairies which had been read to Keller some time earlier. It was found that Keller had made only minute change to common words and phrases and used less common words to say the same thing, suggesting mere alterations to original ideas. Keller used 'vast wealth' instead of 'treasure' (approximately 230 times less common in the language) 'bethought' instead of 'concluded' (approximately $\underline{400}$ times less common) 'bade them' instead of 'told them' (approximately 30 times less common). Keller used the phrase 'ever since that time' whilst Canby chose 'from that time' (the latter 50 times more common than the former). Keller also used 'I cannot imagine' whereas Canby used ' 1 do not know '.'know ' is approximately ten times more common than 'imagine'. Keller relied on a lexis that is less common when compared to Canby's. The Flesch and FleschKincaid readability test showed that Canby's text showing 
more originality compared to Keller's. Canby's text obtained a higher grade on the reading ease scale compared to Keller's. The distinctions between Keller and Canby's text are at the lexical and phrasal level(Coulthard, 2004, p. $\underline{\text { 431) }}$.

\subsection{How the voice Works in Forensic Linguistics}

The voice works because the vocal folds vibrate. In speech we produce a mix of buzzing, popping and hissing. The buzzing is the voicing of speech sounds, the popping is what happens when we produce plosives and the hissing comes from sibilants. We get voiceless plosives and sibilants too. Voice quality varies depending on how open or closed the glottis is during phonation. Voicelessness is just that- the air is passing freely through the glottis from the lungs: the glottis is in its maximally open position. A breathy voice is one in which the glottis remains open and in which the vocal folds flab lossely. A modal voice is one in which the glottis is slightly open, while a creaky voice think of Marilyn Monroe, or Margaret Thatcher at her most hypnotically persuasive. With a breathy voice you will get a hushing sound not unlike wind rushing through an open window throughout the speech sample. On the other hand, to imagine a creaky voice think of the typical expert sitting back in a chair, pontificating to the audience in a low voice, somewhat like Dr. Henry Kissinger's voice. A creaky voice is a croaky type sound at a much lower pitch than normal. Imagine a door that could speak and creak simultaneously (Olsson, 2008a,p.181).

These descriptions are very subjective, but they may help you visualize different voice types. Think of a musical instrument: a cello sounds deeper than a violin because of size, proportions, structure and material used. You can tell them apart even if they are playing the same note. It is the same with voice: two speakers might speak at the same pitch, but they will sound different because of different shape, proportions, size... etc. One speaker will have longer vocal folds than another, a bigger oral cavity, etc. Voice quality is also changed by atmospheric conditions- a violin in damp conditions will sound different in dry conditions, and the human voice will vary according to the conditions in which speech is being made, according to the health of the speaker, tiredness, and so on. Phoenicians have viewed the question of voice quality differently over the years (Olsson, 2008b, p.181).

Ladefoged (1971) developed a simplified continuum of glottal constructions, while Laver (1980) saw possibilities in combing voice types, for example a whispered modal voice. This seems intuitively right, because people do combine different voice styles. In one case a female suspect had been recorded talking on the telephone to her husband. Her voice was mainly modal but when she came to stressing syllables, these were often in a creaky voice. On the other hand, she would often begin an utterance in a breathy voice. On the police interview tape, however, matters were somewhat different. For a start, she spoke in an entirely different register: the informal, casual, wordinitial h-dropping and word-final "-ing" pronounced as "in" was gone. The voice sounded huskier, more persuasive. The responses were delayed, perhaps carefully thought through. The emotional range was different, too. When talking to her husband she was alternately happy, sad, annoyed, enthusiastic, dispirited, bored, etc. In the interview she was much more controlled, formal, and mostly polite, although still displaying some emotion at times. The police interview tape, too, was recorded under completely different acoustic conditions: it was a face-toface interview in a room with fairly flat acoustics. When we speak to people we know well and we are close to, we tend to be much more informal we adapt to their register and they adapt ours. Moreover, talking on a telephone usually involves raising the voice. Mobile (cell) phones are particularly tricky because the distance between the speaker's mouth and the microphone is not constant. The person is often in a public place, may be walking around, moving their head, etc. In the interview the speaker is likely to be tense, controlled, sitting fairly stationary, keeping a more constant distance from the microphone (Olsson, 2008a, p.182).

\section{DATA ANALYSIS AND COLLECTIONS}

\subsection{Introduction}

The following areas of application have different degrees of reliability within the field. Linguists have provided evidence in:

\section{Author identification}

The identification of whether a given individual said or wrote something relies on analysis of their idiolect, or particular patterns of language use (vocabulary, collocations, pronunciation, spelling, grammar) (Olsson,2008b, p.183).

\section{Forensic stylistics}

This discipline subjects written or spoken materials (or both) to scientific analysis for determination and measurement of content, meaning, speaker identification, 
or determination of authorship, in identifying plagiarism (Olsson, 2008a, p.183).

\section{Discourse analysis}

Discourse analysis deals with analyzing written, oral, or sign language use, or any significant event (Olsson, 2008a, p.183).

However, the data are going to be analyzed from discourse point of view particularly assessing language offenders. The data are taken from the legal texts that take place in the court between the judge and the criminal.

\subsection{Data Analysis}

\section{Text No.1:}

All members shall give the United Nations every assistance in any action it takes in accordance with the present Charter, and shall refrain from giving assistance to any state against which the United Nations is taking preventive or enforcement action. (International journal of justice, 2018).

In this text, one can note the use of reiteration mainly in the phrase "United Nations" and the word "assistance". Hence, the repetition of such phrases in the discourse of the legal texts can indicate a main feature of such texts. Thus, another feature of lexical cohesion in this text is that the use of collocation in the same phase that has been mentioned previously. Linguistically, the word "United" is usually associated with "Nations" in such linguistic contexts of the language of the legal texts.

\section{Text No.2:}

At least three months before the date of the election, the Secretary- General of the United Nations shall address a written request to the members of the Permanent Court of Arbitration belonging to the states which are parties to the present Statute, and to the members of the national groups appointed under Article, paragraph, inviting them to undertake, within a given time, by national groups, the nomination of persons in a position to accept the duties of a member of the Court. (International journal of justice, 2018)
In the text no.2, more than three devices of lexical cohesion can be recognized. These devices can be clarified simply as in the word "permanent court that indicates the use of collocation since these two terms usually occur to gather in this context. Then, the use of repetition is also found. The word "court" has been recurred twice in the text above. Finally, the relation of part-whole which is known "metonymy". This relation is concerned with words as parts of the whole as in "members" and the word "court" since members are parts of legal speeches.

\section{Text No.3:}

The members of the court shall be elected by General Assembly and by Security Council from a list of persons nominated by the national groups in the Permanent Court of Arbitration, in accordance with the following provisions. (International journal of justice, 2018).

Clearly stated this text carries the relation of "hyponymy" is employed in this text in which the word "persons" is a branch of "national groups". Again, the use of repletion of the same noun "court" has been used in this text.

\section{Text No.4:}
At every election, the electors shall bear in mind not only that the persons to be elected should individually possess the qualification required, but also that in the body as a whole the representation of the main forms of civilization and of the principal legal systems of the world should be assured. (International journal of justice, 2018).

In this text, one can note the use of reiteration mainly in the phrase "the electors", the repetition of such phrases in the discourse used in the legal situations can indicate a main feature of such speeches. Clearly, stated this text carries the relation of "hyponymy" is employed in this text in which the word "mind" is a part of the body of the word "person".

\section{Text No.5:}

The seat of the Courts shall be established at The Hague. This, however, shall not prevent the Court from sitting and exercising its functions elsewhere whenever 
the Court considers it desirable.

(International journal of justice, 2018).

In this text, one can note the use of paraphrase in which the second sentence summarizes the former statement that opens the text. Another feature of this text is "Pro-form". It is a word or phrase that can take the place of another word (or word group) is a sentence. Pro-form can be identified in this text as in the pronoun "this" that takes place of the former sentence.

\section{Text No.6:}

If the Court includes upon the Bench no judge of the nationality of the parties, each of these parties may proceed to choose a judge. (International journal of justice, 2018).

In this text, one can note the use of the repetition of In the text no.9, the use of "pro-form" is one of the features the words "parties" and "judge". Such repetitions are formed in these texts to constitute the cohesive ties indicating the lexical relations between words in the legal texts.

\section{Text No.7:}

\begin{abstract}
Whenever the construction of the constituent instrument of a public international organization or of an international convention adopted thereunder is in question in a case before the Court, the Register shall so notify the public international organization concerned and shall communicate to it copies of all the written proceedings. (International journal of justice, 2018).
\end{abstract}

The main feature of this text is "Pro-form". As previously mentioned pro-form is a word or phrase that can take the place of another word (or word group) and it can be identified as in conjunction "so" that takes place of the information known to the reader.

\section{Text No.8:}

Whenever a treaty or convention in force provides for reference of matter to a tribunal to have been instituted by the League of Nations, or to the Permanent Court of International Justice, the matter shall, as between the parties to the present Statute, be referred to the International
Court of Justice. (International journal of justice, 2018).

This text is not of much different from the former, the main feature of this text is "Pro-form" its use of this cohesive tie can be seen in the conjunction "as" that takes place of the information known to the reader.

\section{Text No.9:}

When a state which is not a Member of the United Nations is a party to a case, the Court shall fix the amount which that party is to contribute towards the expenses of the Court. This provision shall not apply if such state is bearing a share of the expenses of the Court. (International journal of justice, 2018). here. It is a word or phrase that can take the place of another word (or word group) in a sentence. Pro-form can be identified in this text as in the phrase "if such" that occupies another information features in the text. The cotext plays role in this legal

\section{Text No.10:}

The Register shall also, by means of a special and direct communication, notify any state entitled to appear before the Court or international organization considered by the Court, or, should it not be sitting, by the President, as likely to be able furnish information on the question, that the Court will be prepared to receive, within a time limit to be fixed by the President, written statements, or to hear, at a public sitting to be held for the purpose, oral statements relating to the question. (International journal of Justice, 2018)

In this text, the use of repetition can be recognized particularly in the words like "president", the repetition of such phrases in the legal discourse can indicate a main feature of such speeches. Additionally, the use of "pro-form" can also be identified mainly in "also" that clarifies additional information in this legal text.

\section{Text No.11:}

Amendments to the present Charter shall come into force for all Members of the 
United Nations when they have been adopted by a vote of two thirds of the members of the General Assembly and ratified in accordance with their respective constitutional processes by two thirds of the Members of the United Nations, including all the permanent members of the Security Council. (International journal of justice, 2018).

In this text no.11, one can note the use of the sense relation of "hyponymy". It is employed in the current legal text mainly between the words "two thirds" since the phrase "two thirds" is a part of "all members". However, the formation of these words is understandable via the co-text which shows such relations between lexical items in the text.

\section{Text No.12}

No group may nominate more than four persons, not more than two of whom shall be of their own nationality. In no case may the number of candidates nominated by a group be more than double the number of seats to be filled. (International journal of justice, 2018).

In this text, one can note the use of the sense relation of "hyponymy". It is employed in the current legal text mainly between the words "four persons" that are a part of "group". Thus, the co-text has much to do to clarify such lexical relation with the text to make or show the relationship between the words.

\section{CONCLUSIONS}

This study has reached the following conclusions:

1. The field of Linguistics Forensics is becoming more respected in both the legal systems and academia. According to Dr.Shuy, the number of attorneys and prosecutors calling upon forensic linguist to testify keeps increasing each year.

2. The academic field is also responding and now offers more courses on language and the law, and, according to James Fitzerald, some universities now offer forensics linguistics majors.

3. The major input from forensic linguists is in the form of authorship analysis. For instance, English is the language currently most used by criminals, although it is often not their first language (one needs only to think of the
Nigerian money frauds), so there has been significant investment by the security services of several countries to improve computerized techniques for identifying the first language of writers.

4. So far, the vast majority of forensic linguistic work has been analytic, but recently a group of forensic linguists in the UK has been working with a police Pedophile Unit helping police officers to analyze and then synthesize texts. The police need to be able to emulate in real time the online interactive language of adolescents/children.

5. The work and investigation into Forensic Linguistics conducted over the last decades undoubtedly contributed to establishing the field as a Forensic Science. The future is equally promising, not only because new investigation applied to languages other than English is now regularly published (e.g., Coulthard\&Sousa-Silva, 2014), but also because future technological development will raise new challenges to which Forensic Linguistics will certainly provide new solutions.

\section{REFERENCES}

1.Coulthard, K. (2014). Idiolect and Linguistic Uniqueness: Applied Linguistics

2.Crystal, D. (2008). A Dictionary of Phonetics and Linguistics. Blackwell Press

3.Falzini, W. (2008). The Ransom Notes: An Analysis of Their Content \&"Signature". Oxford: Oxford University Press

4.McMenamin, R. (2002). Forensic Linguistics Advances in Forensic Stylistics. California State University: California

5.Newstein, A. \& Hemant, A. (2012). Forensic Speaker Recognition :LawEnforcement and Counter Terrorism. New York: Springer

6.Olsson, J. (2008a). Forensic Linguistics. London: Continuum International Publishing Group

7.Olsson, J. (2008b). Forensic Linguistics ( $2^{\text {nd }}$ ed.). London: Continuum. Retrieved fromhttps://en.wikipedia.org/wiki/ForensicLinguistics\#Forensic-text-types

8.How does forensic linguistics/stylistics work in criminal issues?. (2014).Retrieved from https://www.enotes.com/homework-help/how-doesforensic-linguistics-stylistics-work-467227 